\title{
Influencing Factor Analysis on the Anomalously Low-Friction Effect in the Block Rock Mass
}

\author{
Liping Li $\mathbb{C}^{1},{ }^{1}$ Jinpeng Wu $\mathbb{D}^{1},{ }^{1}$ Yishan Pan, ${ }^{2}$ and Jupeng Tang ${ }^{1}$ \\ ${ }^{1}$ School of Mechanics and Engineering, Liaoning Technical University, Fuxin 123000, Liaoning, China \\ ${ }^{2}$ School of Physics, Liaoning University, Shenyang 110036, Liaoning, China \\ Correspondence should be addressed to Liping Li; liliping@lntu.edu.cn
}

Received 4 June 2020; Revised 17 August 2020; Accepted 1 September 2020; Published 18 September 2020

Academic Editor: Fengqiang Gong

Copyright (c) 2020 Liping Li et al. This is an open access article distributed under the Creative Commons Attribution License, which permits unrestricted use, distribution, and reproduction in any medium, provided the original work is properly cited.

According to the instability failure of the deep rock mass, a superposition block model of anomalously low-friction effect was established. The numerical results were compared with the previous experiment, which verifies the feasibility and effectiveness of the simulation. A vertical impact and confining pressure were applied to the superimposed block model, and a horizontal static force was applied to the working block (the third block). This study aimed to determine the influence rules of vertical impact energy, confining pressure, and block lithology on the horizontal displacement of the working block and normal force on the contact surface. The results show that, with the increase of the vertical impact energy, the horizontal residual displacement of the working block increases linearly, and the horizontal displacement amplitude increases by the exponential function. The minimum normal force on the contact surface decreases linearly. As the confining pressure increases, the horizontal residual displacement of the working block decreases logarithmically, and the horizontal displacement amplitude decreases linearly. The minimum normal force on the contact surface increases linearly. The horizontal residual displacement and displacement amplitude of the working block in the coal-rock combination are 1.51 times and 1.63 times of the rock mass, and the minimum normal force of the former is 0.84 times of the latter. Coal-rock combination is more prone to the anomalously low-friction effect than the rock mass.

\section{Introduction}

Due to the gradual depletion of shallow resources, deep mining has become the main direction of global resource development. Under dynamic loading, the phenomenon produced by deep rock mass is different from that of shallow rock mass, in which the anomalously low-friction effect is one of the main scientific phenomena of dynamic characteristics of the deep rock mass engineering response. The dynamic impulse acts on the rock block system to make the rock mass vibrate, which causes the relative compaction degree between the rock blocks to change, and, in consequence, the friction between the rock blocks will be greatly reduced, resulting in the friction "disappear" effect [1]. The deep block rock mass is more prone to translation and rotation due to this scientific phenomenon, which leads to anomalously low-friction sliding instability of the rock mass. It will induce dynamic disasters such as anomalously low-friction rock burst.
The anomalously low-friction effect was first proposed by Russian scholars Kurlenya et al. [2, 3]. They verified the existence of the anomalously low-friction effect by establishing a dynamic model of block rock mass. Ujiie revealed the reason for the decrease of dynamic frictional resistance on the fault [4]. Tarasov and Randolph revealed that shearing with very low velocity was regarded as responsible for the high-energy release from deep-seated earthquakes and rock bursts in deep underground mines [5]. Boneh et al. studied the effect of sliding velocity and normal stress of rock blocks on friction strength [6]. Saraikin et al. used the binary finite difference model to solve and analyze the dynamic problem of the surface of the explosion cavity of the bulk material under the action of deep explosion [7]. Rashed and Peng studied the relationship between the violence of coal specimen failure and the interface friction and the width-toheight $(\mathrm{W} / \mathrm{H})$ ratio of the coal specimen. They determined at what $\mathrm{W} / \mathrm{H}$ ratio and interface friction the mode of failure 
changes from violent to nonviolent [8]. Tajduś et al. determined the effect of friction coefficient on the state of stress, which occurs in the vicinity of a normal fault [9]. Ito et al. revealed the mechanism of fault slip-weakening frictional behavior [10]. Eshiet and Sheng studied the effect of joint friction characteristics on the fracture behavior of jointed rock masses [11]. Das et al. evaluated the effect of the inclination of strata and the coal seam on the stability of the surrounding rock and proposed an analysis method for mining stability of the inclined coal seam [12]. Lomas et al. contrasted the coefficient of friction of coke from different coal origins and analyzed the relationship between the coefficient of friction of coke and the blend composition of parent coal [13]. Prassetyo et al. proposed a new coal pillar strength formula, which was based on the effect of coal/roof and coal/roof interface friction on coal pillar strength [14]. Heimisson et al. proposed a fundamentally new instability mechanism, which proved how slow-slip events can form under mild rate-strengthening friction [15]. Pirzada et al. clarified the role of the actual contact area on the friction characteristics of jointed rocks [16].

Academician Qian proposed that the anomalously lowfriction effect was a key scientific issue in deep mining. It is necessary to strengthen research on the mechanism and rules of the anomalously low-friction effect [1]. Wu et al. studied the wave characteristics of block media from an experimental perspective [17]. He et al. obtained the friction variation characteristics of a granite block with a hole in the center, which verified the existence of the anomalously lowfriction effect [18]. Jiang and $\mathrm{Li}$ revealed the triggering mechanism of slip-type rock burst [19]. Li et al. established the theoretical model of the anomalously low-friction effect of block rock mass with overlying rock mass pressure and determined the precondition of producing the anomalously low-friction effect [20].

Scholars have done a lot of research studies on the scientific problem of the anomalously low-friction effect and achieved rich and valuable results. These research results were more from the perspective of verifying the existence of the anomalously low-friction effect and revealing the mechanism of the anomalously low-friction effect, mainly based on experimental analysis. It is noteworthy that scholars have done little research on the influence of different factors on the anomalously lowfriction effect of the deep block rock mass. Therefore, the anomalously low-friction effect superposition block model is established by the numerical simulation analysis method in this paper. A vertical impact and confining pressure are applied to the superimposed block model, and a horizontal static force is applied to the working block. The horizontal displacement of the working block and the normal force on the contact surface are considered as the characteristic parameters of the anomalously low-friction effect. The effects of vertical impact energy, confining pressure, and block lithology on the characteristic parameters under vertical impact disturbance are analyzed. The conclusions obtained have important practical application value for the prediction and prevention of anomalously low-friction rock burst.

\section{Model Establishment and Verification}

2.1. Model Establishment. Using finite difference software FLAC3D, the Mohr-Coulomb model suitable for rock-like materials is selected as the constitutive model. The model consists of five blocks of the same size stacked vertically from top to bottom, and the third block is defined as the working block. Each block is divided into $8 \times 5 \times 5$ units, and contact surfaces are set between adjacent blocks. Static boundary conditions are used to completely constrain the lower boundary of the model and constrain the horizontal displacement of blocks 2 and 4 . The mechanical damping is set to Rayleigh. Monitoring points are set on the model to record the changes of the horizontal displacement of the working block and the normal force on the contact surface under the action of dynamic and static loads. The model and monitoring points are depicted in Figure 1. According to the research conclusion of Li et al. [20], the interaction force between working block and bottom is the smallest when the model is subjected to dynamic and static loads. Therefore, monitoring point (1) is set at contact surface 2, which is between working block and bottom, recording the change of normal force on the contact surface. Monitoring point (2) is set at the central point of the working block to record the horizontal displacement of the working block.

The vertical impact disturbance $P_{\mathrm{v}}(t)$ is applied to the center of the top of the model and its direction straight down. It can be expressed as $P_{\mathrm{v}}(t)=P_{\mathrm{v}} \sin \left(\omega_{\mathrm{v}} t\right)$, where $P_{\mathrm{v}}$ is the vertical impact load amplitude, $\mathrm{N} ; \omega_{\mathrm{v}}=2 \pi f_{\mathrm{v}}$, in which $f_{\mathrm{v}}$ is the vertical impact frequency, $\mathrm{Hz}$; and $t$ is the time, s. The horizontal static force $F$ is applied to the central point of the right side of the working block, and its direction is horizontal to the right. The confining pressure is applied to the front and back sides of the model block, and its direction is perpendicular to the working surface.

2.2. Feasibility Verification. A reasonable numerical simulation method has a guiding role for experimental research and theoretical analysis. Comparing the experimental and numerical simulation results can effectively judge the feasibility of the numerical simulation method. Therefore, the numerical simulation results in this paper are compared with the experimental results in [19] to verify the feasibility of the numerical model in this paper. The model is a vertical block system stacked by five sandstone blocks (with dimensions of $160 \mathrm{~mm} \times 125 \mathrm{~mm} \times 125 \mathrm{~mm}$, each with a weight of $6.2 \mathrm{~kg}$ ). The model parameters are consistent with the experimental parameters. The lithology, quality, and size parameters of the rock block are provided by Jiang and $\mathrm{Li} \mathrm{[19].} \mathrm{The} \mathrm{remaining} \mathrm{me-}$ chanical parameters are determined by Ye et al. [21], as shown in Table 1. The mechanical parameters of the contact surfaces between adjacent blocks are the same, as illustrated in Table 2 .

The horizontal displacement response of the working block under the combined action of vertical impact disturbance and horizontal static force is obtained. Figure 2 shows the relationship curve between the simulation results in this paper and the experimental results in [19] under the same vertical impact disturbance $P_{\mathrm{v}}(t)=180 \mathrm{~mJ}$ and different horizontal static forces $F=50 \mathrm{~N}, 90 \mathrm{~N}, 130 \mathrm{~N}$, and $150 \mathrm{~N}$. 


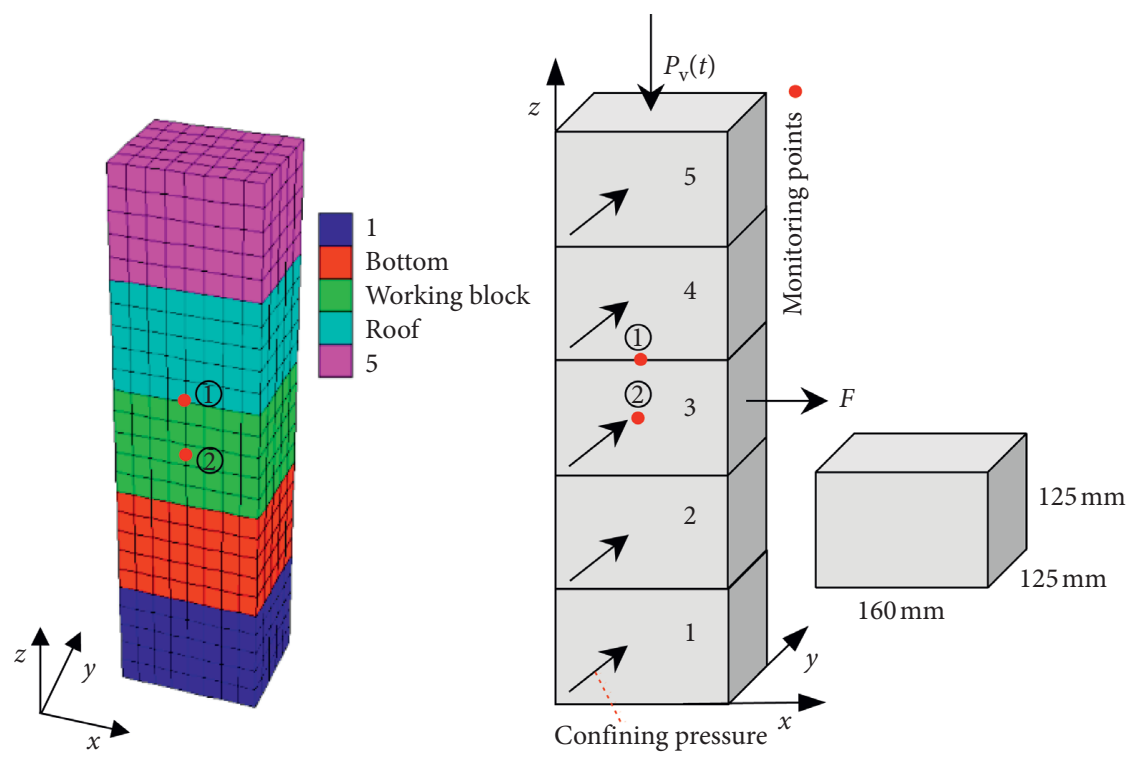

FIgURE 1: Schematic diagram of the model and monitoring points.

TABLE 1: Mechanical parameters of the model.

\begin{tabular}{lc}
\hline Parameter (unit) & Value \\
\hline Cohesion (MPa) & 2.2 \\
Internal friction angle $\left(^{\circ}\right)$ & 30 \\
Tensile strength $(\mathrm{MPa})$ & 0.77 \\
Elastic modulus $(\mathrm{GPa})$ & 3.26 \\
Poisson's ratio & 0.236 \\
\hline
\end{tabular}

TABLE 2: Mechanical parameters of the contact surfaces.

\begin{tabular}{lc}
\hline Parameter (unit) & Value \\
\hline Cohesion $(\mathrm{MPa})$ & 0.11 \\
Internal friction angle $\left(^{\circ}\right)$ & 15 \\
Tensile strength $(\mathrm{MPa})$ & 0.039 \\
$\mathrm{Kn}(\mathrm{Pa} / \mathrm{m})$ & $9.55 e 9$ \\
$\mathrm{Ks}(\mathrm{Pa} / \mathrm{m})$ & $9.55 e 9$ \\
\hline
\end{tabular}

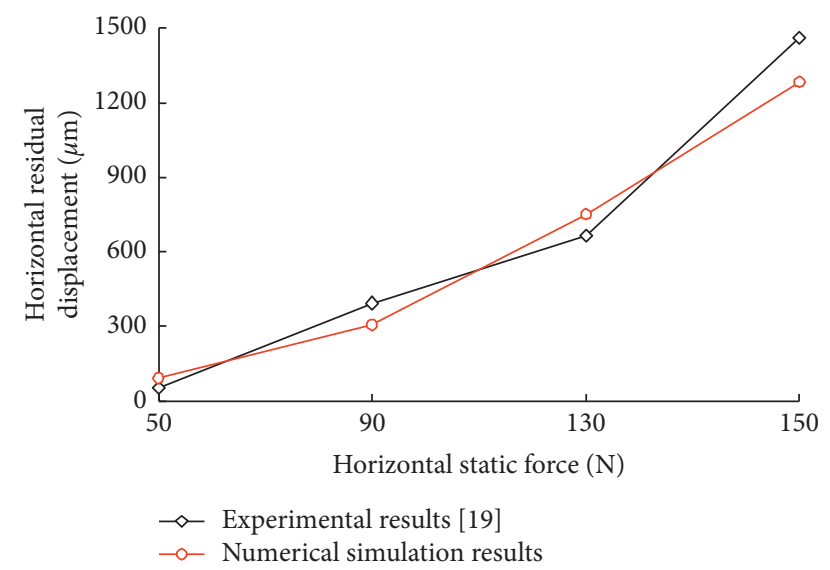

Figure 2: Comparison curve between numerical simulation and experimental results.
In Figure 2, the horizontal residual displacement of the working block increases exponentially with the increase of horizontal static force $F$ when the vertical impact disturbance force $P_{\mathrm{v}}(t)$ is constant. Due to the limitations of equipment and environment during the experiment, the results of the numerical simulation data are different from the results of the experiment. However, it can be seen from Figure 2 that the numerical simulation results are consistent with the overall change trend of the experimental results in [19]. The horizontal residual displacement of the working block increases exponentially with the increase of the horizontal static force $F$. The studies cited above verify the feasibility and effectiveness of the numerical simulation model in this paper.

\section{Result Analysis}

3.1. Effect of the Vertical Impact Energy on the Anomalously Low-Friction Effect. The vertically stacked rocks touch and squeeze each other to form friction. When the rock blocks are subjected to an external force, the critical equilibrium state of the rock blocks will be destroyed if the external force is larger than the friction between the rock blocks, and, in consequence, the rock blocks will move along the direction of the external force. Under the combined action of vertical impact disturbance $P_{\mathrm{v}}(t)$ and horizontal static force $F$, the blocks periodically "move up and down" in the perpendicular direction, which changes the relative compaction degree between blocks. The larger the vertical impact disturbance $P_{\mathrm{v}}(t)$, the stronger the periodic motion intensity of the blocks so that the friction between the blocks changes more obviously.

Figure 3 shows the horizontal displacement-time history curve of the working block of the sandstone block system with the vertical impact energy of $180 \mathrm{~mJ}$ and different horizontal static forces in [19]. It can be seen from the figure 


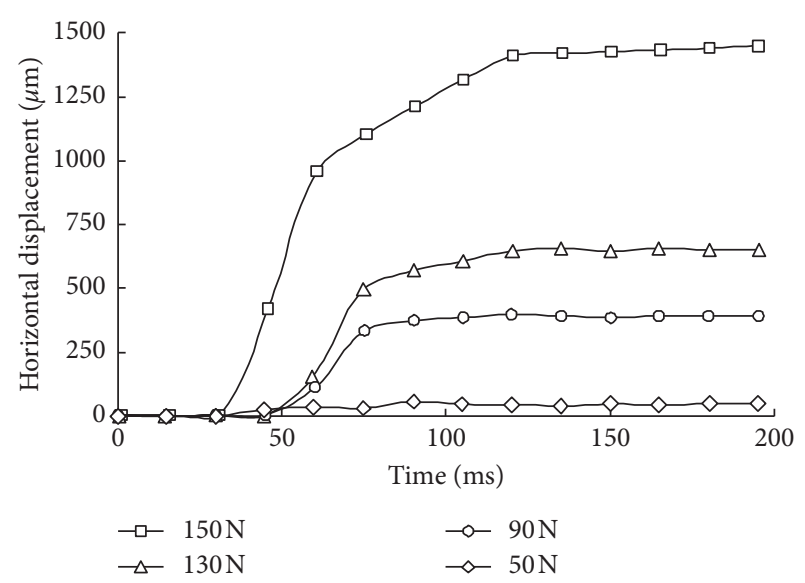

FIgURE 3: Horizontal displacement-time history curve of the working block under different horizontal static forces [19].

that when the horizontal static force $F=50 \mathrm{~N}$, the increase in the horizontal displacement of the working block in the same time period is minimal. Therefore, the horizontal static force is fixed at $50 \mathrm{~N}$; the vertical impact energy $P_{\mathrm{v}}(t)=$ $280 \mathrm{~mJ} 580 \mathrm{~mJ}$, and its gradient is $100 \mathrm{~mJ}$.

The horizontal displacement-time history curve of the working block of the sandstone block system under the constant horizontal static force and different vertical impact energies is shown in Figure 4. The following can be seen from Figure 4:

(1) The horizontal displacement of the working block is closely related to the magnitude of the vertical impact energy. With the increase of the vertical impact energy, the horizontal residual displacement increases linearly, and the displacement amplitude of the working block increases by the exponential function. The results indicate that the vertical impact energy affects the anomalously low-friction effect. The horizontal static force is constant; the greater the vertical impact energy, the more significant the anomalously low-friction effect.

The horizontal displacement-time history curve of the working block under horizontal static force $F=50 \mathrm{~N}$ and vertical impact energy $P_{\mathrm{v}}(\mathrm{t})=380 \mathrm{~mJ}$ is presented in Figure 5. Among them, the maximum value of the horizontal displacement is defined as the horizontal displacement amplitude; the horizontal residual displacement is the displacement when the fluctuation of the horizontal displacement amplitude finally stabilizes.

From Figure 4, it is seen that the change of the vertical impact energy has an influence on the horizontal residual displacement and displacement amplitude of the working block. Both horizontal residual displacement and displacement amplitude increase with the increase of the vertical impact energy. The vertical impact energy increases from $280 \mathrm{~mJ}$ to $580 \mathrm{~mJ}$, and the corresponding horizontal residual displacement is $82.4 \mu \mathrm{m}, 97.8 \mu \mathrm{m}, 131.3 \mu \mathrm{m}$,

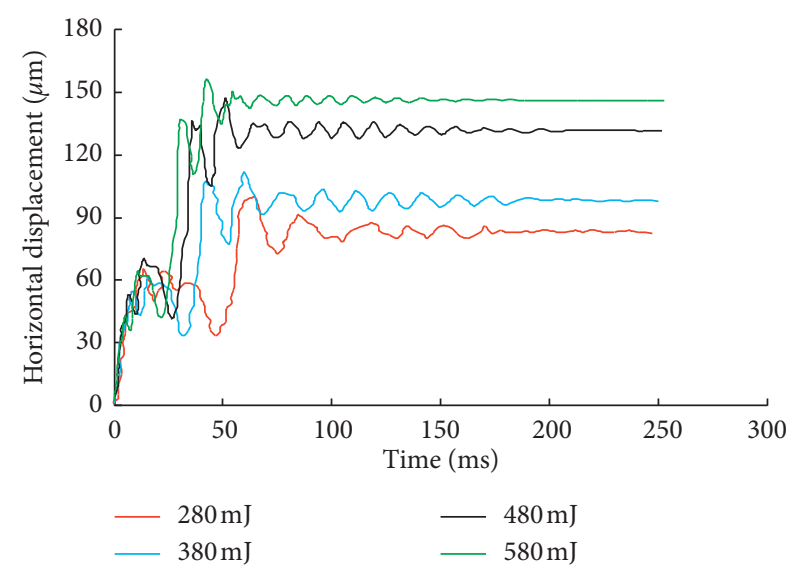

Figure 4: Horizontal displacement-time history curve of the working block under different vertical impact energies.

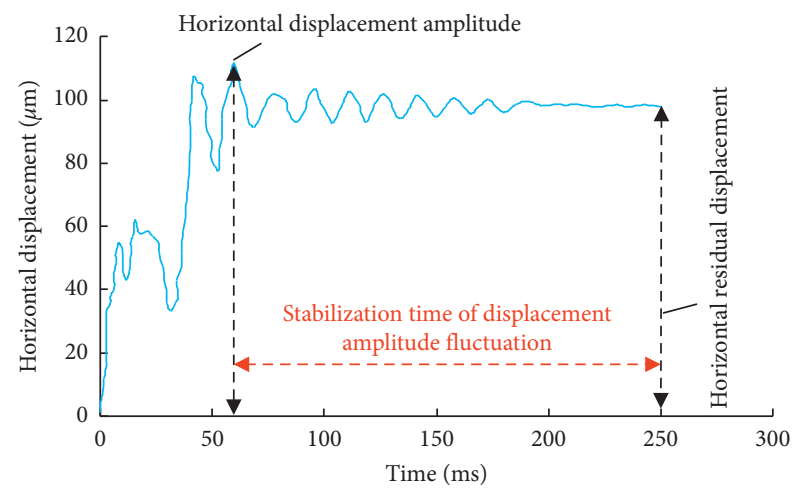

FIgURE 5: Horizontal displacement-time history curve of the working block under the vertical impact energy of $380 \mathrm{~mJ}$.

and $146.1 \mu \mathrm{m}$. Contrast with the former, the residual displacement increased by $18.7 \%, 48.9 \%$, and $77.3 \%$, respectively. The corresponding horizontal displacement amplitude is $99.7 \mu \mathrm{m}, 111.5 \mu \mathrm{m}, 147.2 \mu \mathrm{m}$, and $156.3 \mu \mathrm{m}$, which increased by $11.8 \%, 47.6 \%$, and $56.8 \%$, respectively. Figure 6 shows the relation curve between the vertical impact energy and the horizontal residual displacement and displacement amplitude of the working block.

It can be found from Figure 6 that there is a linear function increase relationship between the horizontal residual displacement and the vertical impact energy. Its correlation equation is $y=0.2246 x+17.822$, and the correlation coefficient is 0.9738 . There is an exponential function increase relationship between the horizontal displacement amplitude and the vertical impact energy. Its correlation equation is $y=62.911 \mathrm{e}^{0.0016 \mathrm{x}}$, and the correlation coefficient is 0.9437 . Because the system is affected by the vertical impact disturbance, the blocks periodically "move up and down" in the perpendicular direction, which changes the relative compaction degree between blocks. When the relative detachment degree between the blocks is the 


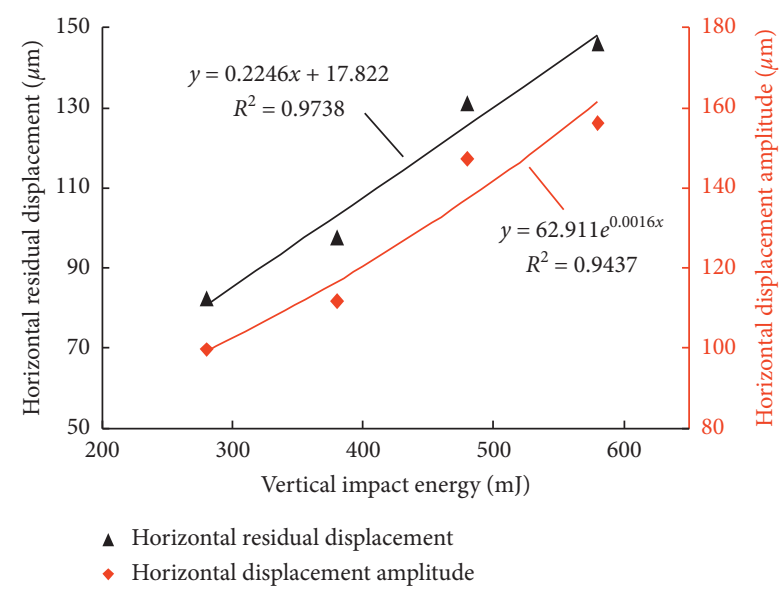

FIgURE 6: Relation curve between the vertical impact energy and the horizontal residual displacement and displacement amplitude of the working block.

largest, the horizontal movement tendency of the working block is the most obvious under the action of the horizontal static force. Sliding instability, which induces anomalously low-friction rock burst, can occur easily between blocks. As a result, with the increase of the vertical impact energy, the horizontal residual displacement and displacement amplitude of the working block increase. The larger the vertical impact energy is, the more likely the anomalously low-friction effect is to induce between rock blocks.

(2) As the vertical impact energy increases, the time of the maximum horizontal displacement amplitude of the working block decreases exponentially. The stabilization time of displacement amplitude fluctuation increases by the exponential function with the increase of the vertical impact energy.

Figure 7 shows the relation curve between the vertical impact energy and the time of the maximum horizontal displacement amplitude and stabilization time of displacement amplitude fluctuation of the working block. Taking Figure 5 as an example, the time when the displacement amplitude appears in the horizontal displacement-time history curve of the working block is defined as the time of the maximum horizontal displacement amplitude. The interval time between the moments of the maximum displacement amplitude and the stable residual displacement is the stabilization time of displacement amplitude fluctuation.

It can be seen from Figure 7 that the change of the vertical impact energy has an influence on the time of the maximum horizontal displacement amplitude and stabilization time of displacement amplitude fluctuation of the working block. The vertical impact energy increases from $280 \mathrm{~mJ}$ to $580 \mathrm{~mJ}$, and the time of the maximum horizontal displacement amplitude is $64.3 \mathrm{~ms}, 59.7 \mathrm{~ms}, 51.1 \mathrm{~ms}$, and $42.4 \mathrm{~ms}$. There is an exponential function decrease relationship between

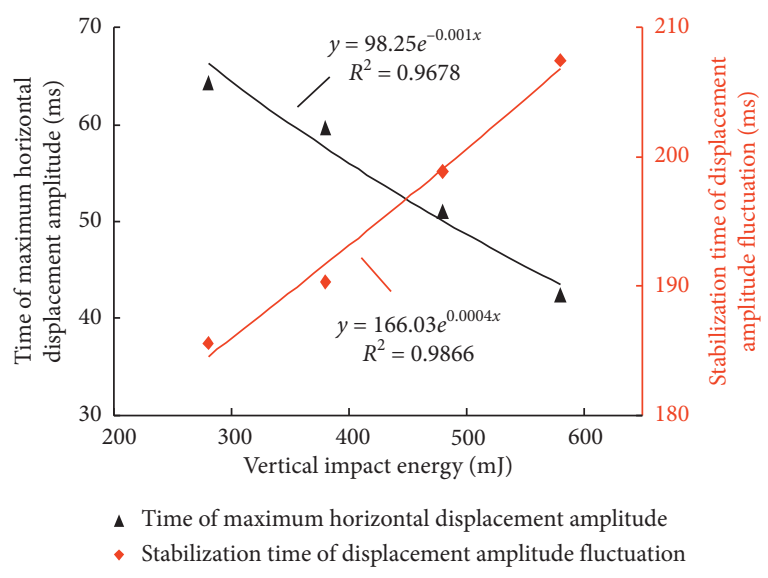

FIgURE 7: Relation curve between the vertical impact energy and the time of the maximum horizontal displacement amplitude and stabilization time of displacement amplitude fluctuation.

the time of the maximum horizontal displacement amplitude and the vertical impact energy. Its correlation equation is $y=98.25 \mathrm{e}^{-0.001 \mathrm{x}}$, and the correlation coefficient is 0.9678 . The stabilization time of displacement amplitude fluctuation is $185.6 \mathrm{~ms}$, $190.3 \mathrm{~ms}, 198.9 \mathrm{~ms}$, and $207.5 \mathrm{~ms}$. There is an exponential function increase relationship between the stabilization time of displacement amplitude fluctuation and the vertical impact energy. Its correlation equation is $y=166.03 \mathrm{e}^{0.0004 \mathrm{x}}$, and the correlation coefficient is 0.9866 . In summary, the rock block has the characteristics of short occurrence time of the horizontal displacement amplitude and long fluctuation time of the displacement amplitude under high-energy vertical impact disturbance.

Monitoring and early warning of rock burst is the foundation for prevention and treatment of the rock burst. However, the technical means of stress monitoring plays a major role in monitoring and early warning of the rock burst. As shown in Figure 1 , monitoring point (1) is set between block 3 and block 4 . The monitoring point is used to monitor the normal force on the contact surface after the block is disturbed by the vertical impact, so as to judge the occurrence of the anomalously low-friction effect. The time history curve of the normal force on the contact surface with the horizontal static force $F=50 \mathrm{~N}$ and the vertical impact energy $P_{\mathrm{v}}(t)=$ $380 \mathrm{~mJ}$ is plotted in Figure 8.

In Figure 8, the initial and final values of the normal force on the contact surface fluctuate near the equilibrium position $F_{\mathrm{N}}=124 \mathrm{~N}$. The simulation results of the normal force on the contact surface are consistent with its actual stress state. The block system is affected by the vertical impact, which changes the relative compaction degree between blocks. $F_{\mathrm{N}}=124 \mathrm{~N}$ is used as the equilibrium point to judge the compression state between blocks. $F_{\mathrm{N}}>124 \mathrm{~N}$ indicates that blocks 3 and 4 are 


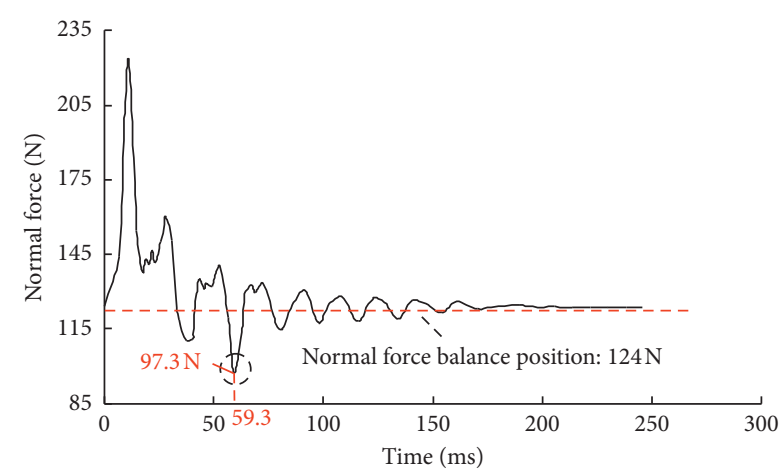

Figure 8: Time history curve of the normal force on the contact surface with the vertical impact energy of $380 \mathrm{~mJ}$.

compressed in the normal direction, and the blocks are in the compression state. $F_{\mathrm{N}}<124 \mathrm{~N}$ demonstrates that blocks 3 and 4 are pulled in the normal direction, and the blocks are in the separation state.

(3) The minimum normal force on the contact surface is closely related to the magnitude of the vertical impact energy. With the increase of the vertical impact energy, the minimum normal force on the contact surface decreases linearly. The horizontal static force is constant; the greater the vertical impact energy, the more significant the anomalously low-friction effect.

The minimum normal force on the contact surface reflects the magnitude of the decline in the normal force between blocks. The normal force is a constant value, and the magnitude of the decline in the normal force increases as the minimum normal force decreases. As a result, the degree of separation between the blocks increases, which in turn reduces the friction between the blocks. Under the action of the horizontal static force, the working block slides nonlinearly along the contact surface, resulting in the anomalously low-friction effect and causing the anomalously lowfriction rock burst. In Figure 8, when the vertical impact energy is $380 \mathrm{~mJ}$, the normal force on the contact surface reaches a minimum value of $97.3 \mathrm{~N}$ at $59.3 \mathrm{~ms}$. At the moment, the degree of separation between blocks 3 and 4 is the largest.

Different vertical impact energies affect the minimum normal force on the contact surface. Figure 9 shows the relation curve between the vertical impact energy and the minimum normal force on the contact surface. From Figure 9, it can be seen that the vertical impact energy increases from $280 \mathrm{~mJ}$ to $580 \mathrm{~mJ}$, and the minimum normal force is 111.8 N, 97.3 N, 80.6 N, and 69.2 N. Contrast with the former, the minimum normal force increased by $-12.9 \%$, $-27.9 \%$, and $-38.1 \%$, respectively. There is an exponential function decrease relationship between the minimum normal force and the vertical impact energy. Its correlation equation is $y=177.69 \mathrm{e}^{-0.002 \mathrm{x}}$, and the correlation coefficient is 0.9969 . Therefore, the horizontal static force is constant. The minimum normal force on the contact surface decreases as the vertical impact energy increases. In this way, the degree of separation between the blocks is increased, and the anomalously low-friction effect is more significant.

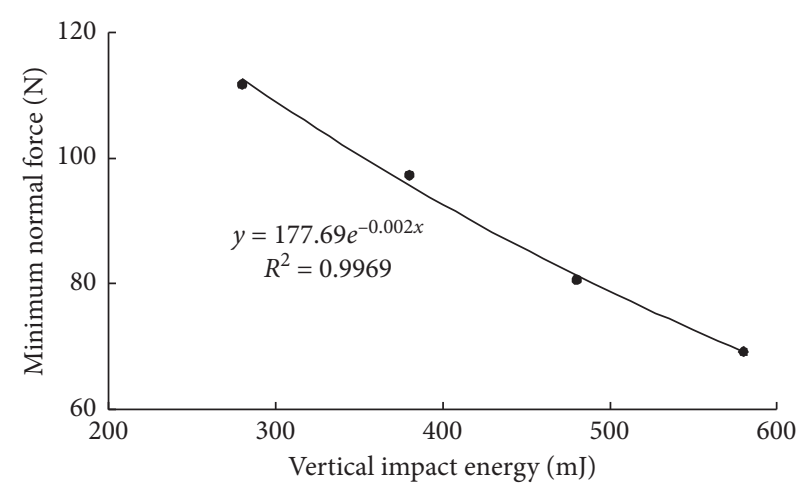

FIgURE 9: Relation curve between the vertical impact energy and the minimum normal force on the contact surface.

3.2. Effect of the Confining Pressure on the Anomalously LowFriction Effect. Deep mining enters $800 \mathrm{~m} \sim 1000 \mathrm{~m}$, and the maximum confining pressure of the rock mass is $20 \mathrm{MPa}$ [22]. Rock mass excavation reduces the confining pressure on the rock mass and weakens the stability of the rock mass. The intense mining disturbance causes large-scale instability of the rock mass, which is very easy to cause anomalously low-friction rock burst.

The horizontal static force and the vertical impact energy are fixed values, respectively, $50 \mathrm{~N}$ and $380 \mathrm{~mJ}$. The confining pressures are specified as $5 \mathrm{MPa}, 10 \mathrm{MPa}, 15 \mathrm{MPa}$, and $20 \mathrm{MPa}$. The variation characteristics of the horizontal displacement of the working block and time history curve under different confining pressures are illustrated in Figure 10.

(1) The horizontal displacement of the working block is closely related to the magnitude of the confining pressure. With the increase of the confining pressure, the horizontal residual displacement and displacement amplitude of the working block decrease by logarithmic and linear functions. The horizontal static force and vertical impact energy are constant; the smaller the confining pressure, the more significant the anomalously low-friction effect.

From Figure 10, it is seen that the change of the confining pressure has an influence on the horizontal residual displacement and horizontal displacement amplitude of the working block. Both the horizontal residual displacement and the horizontal displacement amplitude decrease with the increase of the confining pressure. The confining pressure increases from $5 \mathrm{MPa}$ to $20 \mathrm{MPa}$, and the corresponding horizontal residual displacement is $113.5 \mu \mathrm{m}$, $89.2 \mu \mathrm{m}, 70.63 \mu \mathrm{m}$, and $60.7 \mu \mathrm{m}$. Contrast with the former, the residual displacement increased by $-21.4 \%,-37.8 \%$, and $-46.5 \%$, respectively. The corresponding horizontal displacement amplitude is $127.9 \mu \mathrm{m}, 112.2 \mu \mathrm{m}, 91.6 \mu \mathrm{m}$, and $73.4 \mu \mathrm{m}$, which increased by $-12.3 \%,-28.4 \%$, and $-42.6 \%$, respectively. Figure 11 shows the relation curve between the confining pressure and the horizontal residual displacement and displacement amplitude of the working block. 


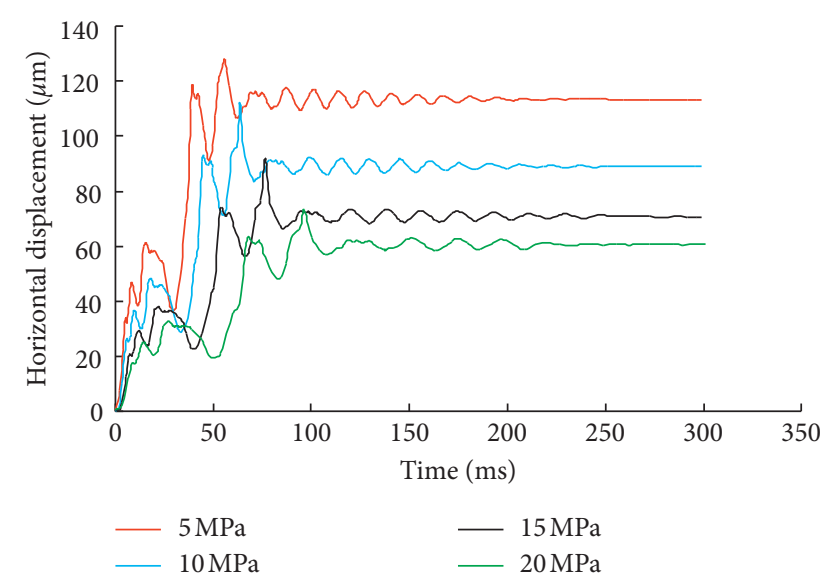

FIgURE 10: Horizontal displacement of the working block and time history curve under different confining pressures.

It can be seen from Figure 11 that there is a logarithmic function decrease relationship between the horizontal residual displacement and the confining pressure. Its correlation equation is $y=-38.58 \ln (\mathrm{x})+176.24$, and the correlation coefficient is 0.9969 . There is a linear function decrease relationship between the horizontal displacement amplitude and the confining pressure. Its correlation equation is $y=-3.682 x+147.3$, and the correlation coefficient is 0.9975 . Therefore, with the increase of the confining pressure, the horizontal residual displacement and displacement amplitude of the working block decrease. The smaller the confining pressure is, the more likely the anomalously lowfriction effect is to induce between rock blocks.

(2) As the confining pressure increases, the time of the maximum horizontal displacement amplitude of the working block increases exponentially. The stabilization time of displacement amplitude fluctuation decreases by the linear function with the increase of the confining pressure.

Figure 12 shows the relation curve between the confining pressure and the time of the maximum horizontal displacement amplitude and stabilization time of displacement amplitude fluctuation of the working block. It can be found from Figure 12 that the change of the confining pressure has an influence on the time of the maximum horizontal displacement amplitude and stabilization time of displacement amplitude fluctuation of the working block. The confining pressure increases from $5 \mathrm{MPa}$ to $20 \mathrm{MPa}$, and the time of the maximum horizontal displacement amplitude is $55.8 \mathrm{~ms}, 63.5 \mathrm{~ms}, 76.4 \mathrm{~ms}$, and $96.2 \mathrm{~ms}$. There is an exponential function increase relationship between the time of the maximum horizontal displacement amplitude and the confining pressure. Its correlation equation is $y=45.384 \mathrm{e}^{0.0363 \mathrm{x}}$, and the correlation coefficient is 0.9845 . The stabilization time of displacement amplitude fluctuation is $244.2 \mathrm{~ms}, 236.5 \mathrm{~ms}, 223.6 \mathrm{~ms}$,

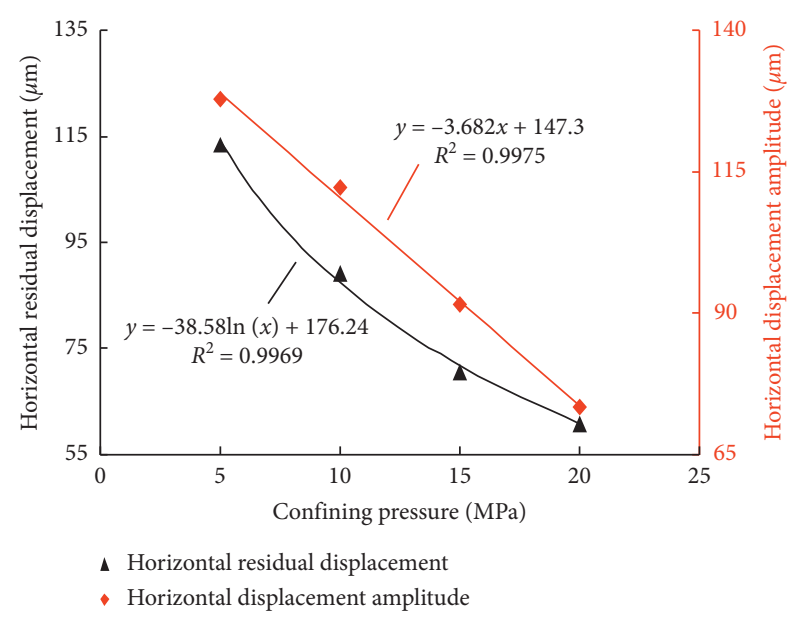

FIGURE 11: Relation curve between the confining pressure and the horizontal residual displacement and displacement amplitude of the working block.

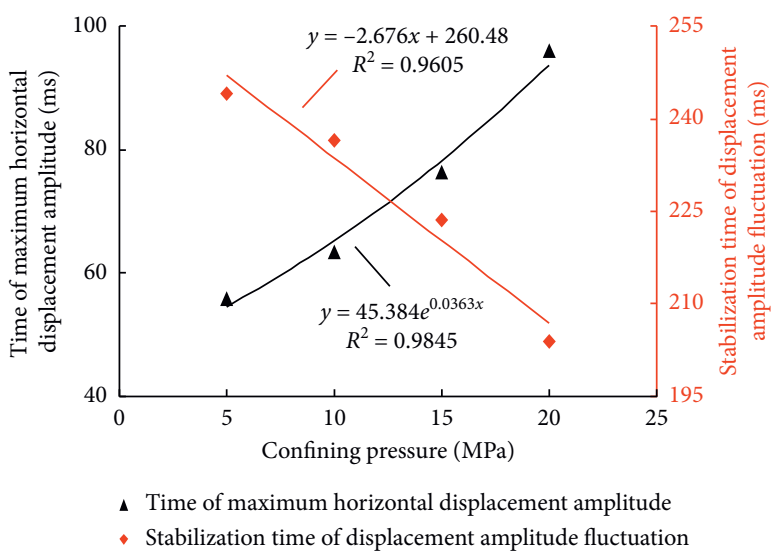

FIgURE 12: Relation curve between the confining pressure and the time of the maximum horizontal displacement amplitude and stabilization time of displacement amplitude fluctuation.

and $203.8 \mathrm{~ms}$. There is a linear function decrease relationship between the stabilization time of displacement amplitude fluctuation and the confining pressure. Its correlation equation is $y=-2.676 x+260.48$, and the correlation coefficient is 0.9605 . To sum up, the rock block has the characteristics of short occurrence time of the horizontal displacement amplitude and long fluctuation time of the displacement amplitude under the vertical impact disturbance with low confining pressure.

(3) The minimum normal force on the contact surface is closely related to the magnitude of the confining pressure. With the increase of the confining pressure, the minimum normal force on the contact surface increases linearly. The smaller the confining pressure, the more significant the anomalously lowfriction effect.

The horizontal static force and vertical impact energy are fixed values, respectively, $50 \mathrm{~N}$ and $380 \mathrm{~mJ}$, and the confining 
pressure is $10 \mathrm{MPa}$. The time history curve of the normal force on the contact surface is indicated in Figure 13.

In Figure 13, the normal force on the contact surface reaches a minimum value of $106.1 \mathrm{~N}$ at $63.3 \mathrm{~ms}$. At this time, the degree of separation between blocks 3 and 4 is the largest. Different confining pressures affect the minimum normal force on the contact surface. The relation curve between the confining pressure and the minimum normal force on the contact surface is plotted in Figure 14.

It can be seen from Figure 14 that the confining pressure increases from $5 \mathrm{MPa}$ to $20 \mathrm{MPa}$, and the minimum normal force is $102.5 \mathrm{~N}, 106.1 \mathrm{~N}, 109.7 \mathrm{~N}$, and 114.6 N. Contrast with the former, the minimum normal force increased by $3.5 \%$, $7.0 \%$, and $11.8 \%$, respectively. There is an exponential function increase relationship between the minimum normal force and the confining pressure. Its correlation equation is $y=98.626 \mathrm{e}^{0.0074 \mathrm{x}}$, and the correlation coefficient is 0.9959 . Therefore, the horizontal static force and vertical impact energy are constant, and the minimum normal force on the contact surface decreases as the confining pressure decreases. In this way, the degree of separation between the blocks is increased, and the anomalously low-friction effect is more significant.

As mentioned above, confining pressure affects the anomalously low-friction effect. Moreover, the smaller the confining pressure is, the easier it is to produce the anomalously low-friction effect. Rock mass can easily cause sliding instability under low confining pressure, and the possibility of inducing the anomalously low-friction rock burst is higher. The conclusions obtained in this paper are consistent with the experimental results in [23]: "as the confining pressure decreases, the severity of rock mass failure increases, which is more likely to induce high-energy rock burst accidents."

\subsection{Effect of Block Lithology on the Anomalously Low-Friction} Effect. With the increase of mining depth, the rock layer structure gradually tends to be block system medium [1]. The structure of deep strata is complex, which is usually composed of rock blocks of different lithology. When the rock layer is disturbed by strong impacts such as blasting and mine earthquake, the degree of vibration separation between rock blocks is different due to different lithology. It is of great significance to study the influence of block lithology on the anomalously low-friction effect to prevent the occurrence of anomalously low-friction rock burst under deep geological conditions.

(1) The horizontal displacement of the working block is closely related to the lithology of the rock block. The horizontal residual displacement and displacement amplitude of the working block are significantly differentiated by rock lithology. The stress environment is consistent, and the influence of complex lithology combination on the anomalously lowfriction effect is greater than that of single lithology combination. Coal-rock combination is more prone to the anomalously low-friction effect than the rock

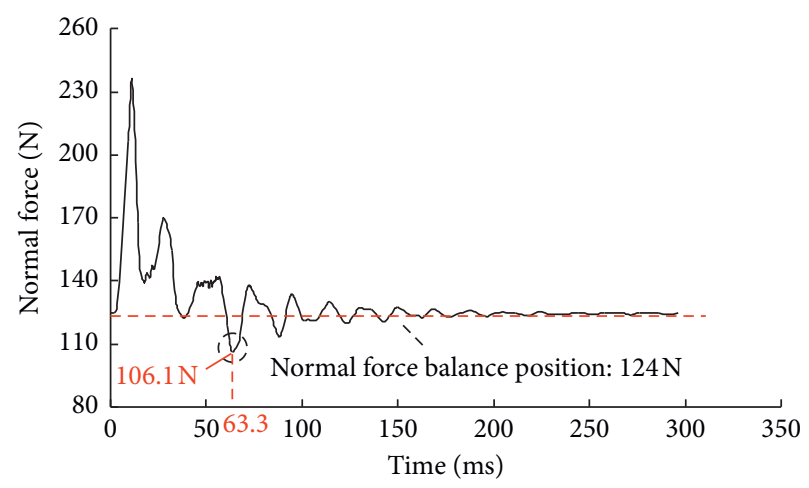

FIgURE 13: Time history curve of the normal force on the contact surface with the confining pressure of $10 \mathrm{MPa}$.

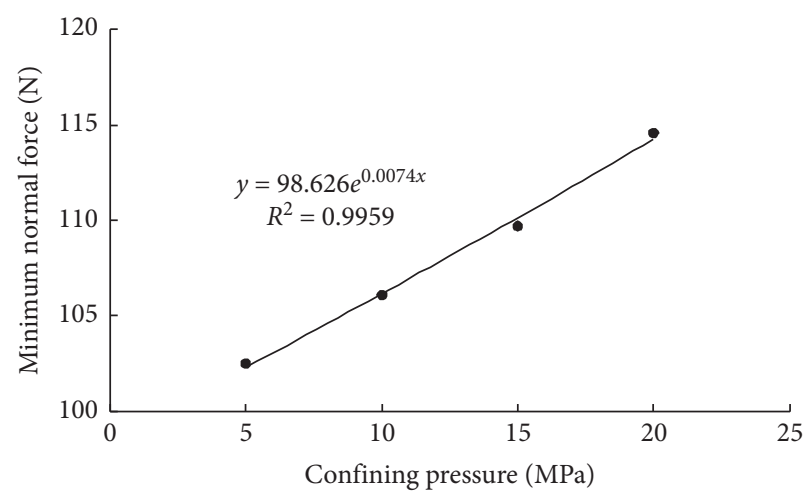

FIgURE 14: Relation curve between the confining pressure and the minimum normal force on the contact surface.

mass, while the intensity of the anomalously lowfriction effect of coal-rock combination is stronger.

During the analysis, the lithology of roof, working block, and bottom is changed in turn. Other variables remain unchanged. The simulation results obtained are compared with the results of the single lithology combination (all blocks are sandstone), which can be used to summarize the influence rules of the block lithology changes on the anomalously low-friction effect. The combination modes of block lithology are shown in Table 3. Table 4 shows the mechanical parameters of coal and mudstone. The mechanical parameters of the contact surface are illustrated in Table 5.

Figure 15 shows the schematic diagram of anomalously low-friction rock burst. Among them, the lithology of roof, coal seam, and bottom is different; the roof is subjected to vertical disturbance caused by roof fracture, and the coal seam is subjected by the horizontal static force. Under the vertical disturbance, the friction between the coal seam and the roof and the bottom is weakened. The coal seam can easily slide along the contact surface when it is suffered by the horizontal static force, resulting in anomalously low-friction rock burst. 
TABle 3: Combination modes of block lithology.

\begin{tabular}{|c|c|c|c|}
\hline & Roof & Working block & Bottom \\
\hline Combination 1: mudstone + sandstone + sandstone & Mudstone & Sandstone & Sandstone \\
\hline Combination 2: sandstone + coal + sandstone & Sandstone & Coal & Sandstone \\
\hline Combination 3: sandstone + sandstone + mudstone & Sandstone & Sandstone & Mudstone \\
\hline
\end{tabular}

TABLE 4: Mechanical parameters of coal and mudstone.

\begin{tabular}{lcc}
\hline & Coal & Mudstone \\
\hline Cohesion $(\mathrm{MPa})$ & 0.8 & 1.2 \\
Internal friction angle $\left(^{\circ}\right)$ & 26 & 28 \\
Tensile strength $(\mathrm{MPa})$ & 0.21 & 0.69 \\
Elastic modulus $(\mathrm{GPa})$ & 1.27 & 1.85 \\
Poisson's ratio & 0.284 & 0.245 \\
\hline
\end{tabular}

TABLE 5: Mechanical parameters of the contact surface.

\begin{tabular}{lccc}
\hline & $\begin{array}{c}\text { Combination 1: } \\
\text { mudstone + sandstone + sandstone }\end{array}$ & $\begin{array}{c}\text { Combination 2: } \\
\text { sandstone + coal + sandstone }\end{array}$ & $\begin{array}{c}\text { Combination 3: } \\
\text { sandstone + sandstone + mudstone }\end{array}$ \\
\hline Cohesion $(\mathrm{MPa})$ & 0.06 & 0.11 & 0.11 \\
Internal friction angle $\left(^{\circ}\right)$ & 14 & 15 & 15 \\
Tensile strength $(\mathrm{MPa})$ & 0.035 & 0.039 & 0.039 \\
$\mathrm{Kn}(\mathrm{Pa} / \mathrm{m})$ & $5.47 e 9$ & $9.55 e 9$ & $9.55 e 9$ \\
$\mathrm{Ks}(\mathrm{Pa} / \mathrm{m})$ & $5.47 e 9$ & $9.55 e 9$ & $9.55 e 9$ \\
\hline
\end{tabular}

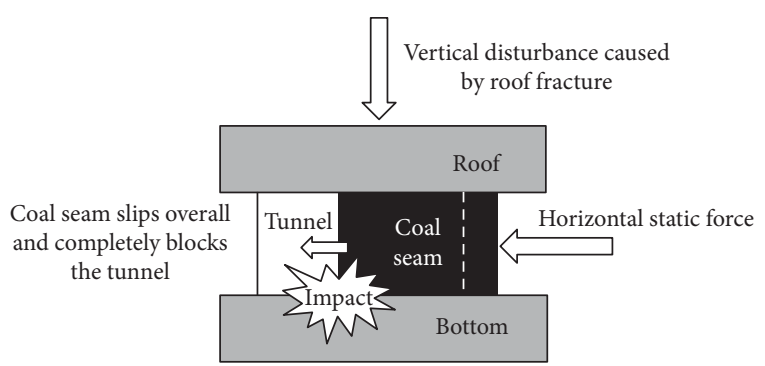

FIGURE 15: Schematic diagram of anomalously low-friction rock burst.

The horizontal static force, vertical impact energy, and confining pressure are fixed values, respectively, $50 \mathrm{~N}, 380 \mathrm{~mJ}$, and $10 \mathrm{MPa}$. The influence rules of rock block lithology on the horizontal displacement of the working block are studied.

Different lithology of the rock blocks not only affects the horizontal residual displacement and displacement amplitude of the working block but also affects the time of the maximum horizontal displacement amplitude and stabilization time of displacement amplitude fluctuation of the working block. Table 6 shows the changes of the horizontal residual displacement and horizontal displacement amplitude of the working block under different lithology. The changes of the time of the maximum horizontal displacement amplitude and stabilization time of displacement amplitude fluctuation of the working block under different lithology are given in Table 7.

As can be seen from Tables 6 and 7, the horizontal residual displacement and displacement amplitude of the working block with complex lithology combination are higher than those of the single lithology combination (all blocks are sandstone). Considering the time of the maximum horizontal displacement amplitude of the working block, the complex lithology combination is lower than the single lithology combination. The stabilization time of displacement amplitude fluctuation of the former is longer than that of the latter. Comparing the horizontal displacement of the three groups of different lithology combinations, it is noteworthy that the coal-rock combination (combination 2) changes significantly more than the rock mass (combination 1 and combination 3) from the displacement perspective or time perspective. The horizontal residual displacement and displacement amplitude of the working block of the coal-rock combination are higher than those of the rock mass (by 1.13, 1.51 times and 1.22, 1.63 times, respectively). The stabilization time of displacement amplitude fluctuation of the coal-rock combination is longer compared to the rock mass by 1.08 and 1.15 times. The time of the maximum horizontal displacement amplitude of the coal-rock combination is the shortest: $15.4 \mathrm{~ms}$. It is 
TABLE 6: Horizontal residual displacement and displacement amplitude of the working block under different lithology.

\begin{tabular}{lcc}
\hline & Residual displacement $(\mu \mathrm{m})$ & Displacement amplitude $(\mu \mathrm{m})$ \\
\hline Single lithology: all blocks are sandstone & 89.2 & 112.2 \\
Combination 1: mudstone + sandstone + sandstone & 193.6 & 196.1 \\
Combination 2: sandstone + coal + sandstone & 217.9 & 238.6 \\
Combination 3: sandstone + sandstone + mudstone & 144.7 & 146.3 \\
\hline
\end{tabular}

TABLE 7: Time of the maximum horizontal displacement amplitude and stabilization time of displacement amplitude fluctuation of the working block under different lithology.

\begin{tabular}{|c|c|c|c|c|}
\hline & $\begin{array}{l}\text { Single } \\
\text { lithology: all } \\
\text { blocks are } \\
\text { sandstone } \\
\end{array}$ & $\begin{array}{c}\text { Combination } 1 \text { : } \\
\text { mudstone }+ \text { sandstone }+ \text { sandstone }\end{array}$ & $\begin{array}{c}\text { Combination 2: } \\
\text { sandstone }+ \text { coal + sandstone }\end{array}$ & $\begin{array}{c}\text { Combination 3: } \\
\text { sandstone + sandstone + mudstone }\end{array}$ \\
\hline $\begin{array}{l}\text { Time of the } \\
\text { maximum } \\
\text { horizontal } \\
\text { displacement } \\
\text { amplitude (ms) }\end{array}$ & 63.5 & 37.3 & 15.4 & 52.5 \\
\hline $\begin{array}{l}\text { Stabilization } \\
\text { time of } \\
\text { displacement } \\
\text { amplitude } \\
\text { fluctuation (ms) }\end{array}$ & 236.5 & 262.7 & 284.6 & 247.5 \\
\hline
\end{tabular}

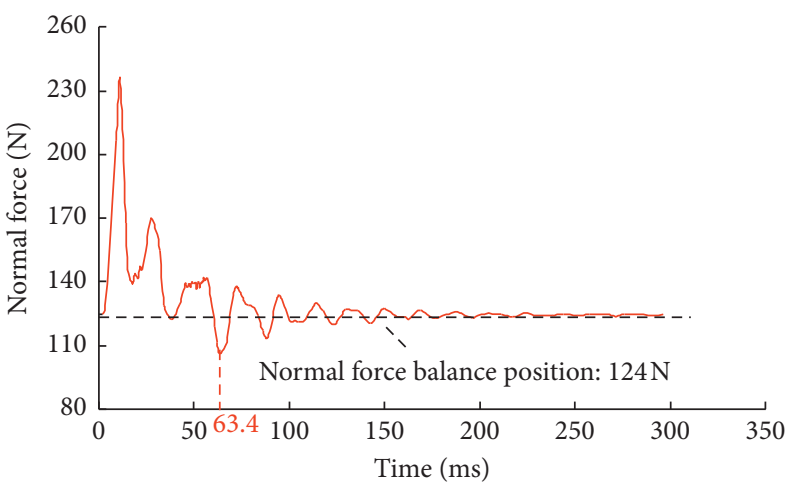

(a)

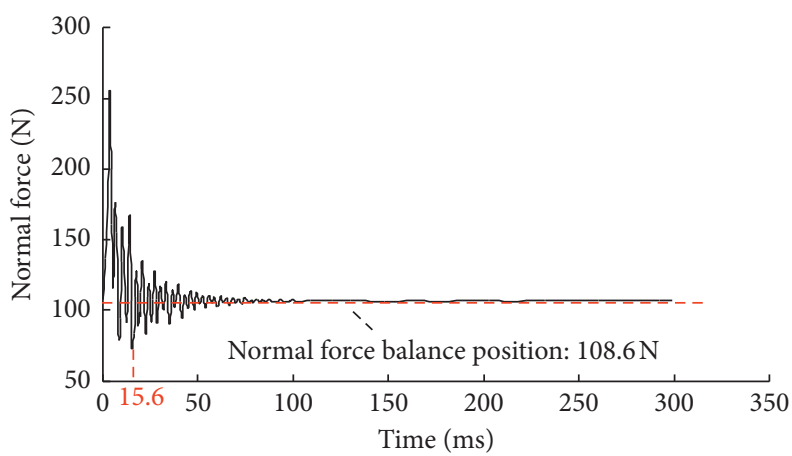

(c)

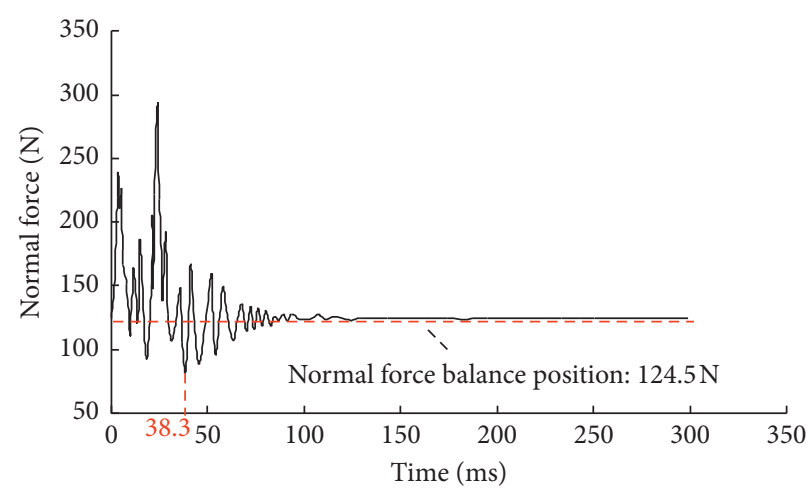

(b)

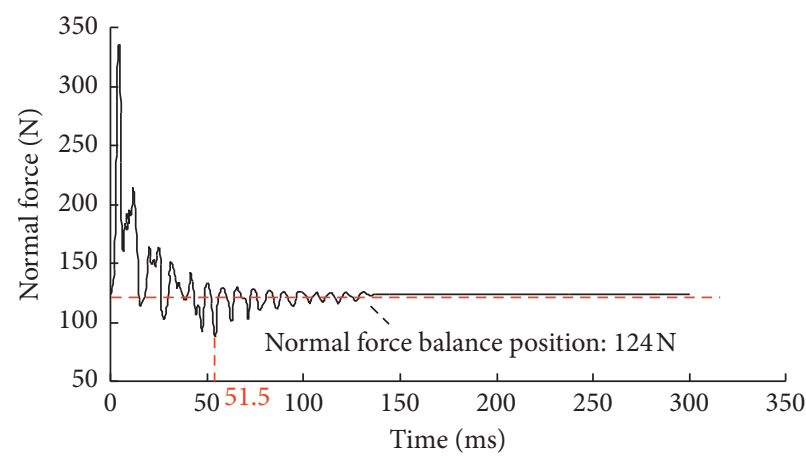

(d)

Figure 16: Time history curve of the normal force on the contact surface under different lithology. (a) Single lithology: all blocks are sandstone. (b) Combination 1: mudstone + sandstone + sandstone. (c) Combination 2: sandstone + coal + sandstone. (d) Combination 3: sandstone + sandstone + mudstone. 
TABLE 8: Minimum normal force on the contact surface under different lithology.

\begin{tabular}{|c|c|c|c|c|}
\hline & $\begin{array}{l}\text { Single } \\
\text { lithology: all } \\
\text { blocks are } \\
\text { sandstone }\end{array}$ & $\begin{array}{l}\text { Combination } 1 \text { : } \\
\text { mudstone }+ \text { sandstone }+ \text { sandstone }\end{array}$ & $\begin{array}{c}\text { Combination 2: } \\
\text { sandstone + coal + sandstone }\end{array}$ & $\begin{array}{c}\text { Combination 3: } \\
\text { sandstone }+ \text { sandstone }+ \text { mudstone }\end{array}$ \\
\hline $\begin{array}{l}\text { Minimum } \\
\text { normal force } \\
(\mathrm{N})\end{array}$ & 106.2 & 81.5 & 73.1 & 87.2 \\
\hline
\end{tabular}

longer than the rock mass, i.e., combination 1 and combination 3 , by 0.41 times and by 0.29 times.

In general, the stress environment is the same, and the influence of complex lithology combination on the anomalously low-friction effect is more significant than that of single lithology combination. Coalrock combination is more prone to the anomalously low-friction effect than the rock mass, while the intensity of the anomalously low-friction effect of coal-rock combination is stronger.

(2) The minimum normal force on the contact surface is closely related to the lithology of the rock block. The minimum normal force on the contact surface is significantly differentiated by rock lithology. The stress environment is consistent, and the influence of complex lithology combination on the anomalously low-friction effect is more significant than that of single lithology combination. Coal-rock combination is more prone to the anomalously low-friction effect than the rock mass, while the intensity of the anomalously low-friction effect of coal-rock combination is stronger.

The horizontal static force, vertical impact energy, and confining pressure are fixed values, respectively, $50 \mathrm{~N}$, $380 \mathrm{~mJ}$, and $10 \mathrm{MPa}$. The influence rules of rock block lithology on the normal force on the contact surface are studied. The time history curve of the normal force on the contact surface under different lithology is plotted in Figure 16. The normal force at the equilibrium position is used as the basis for judging the compression state between blocks, which is of great significance for analyzing the anomalously low-friction effect of the block rock mass. In the static equilibrium state, due to different densities of sandstone, coal, and mudstone, the normal force at the equilibrium position is different (see Figures 16(b)-16(d)).

Under dynamic load, the normal force on the contact surface is closely related to the relative compaction degree between the rock blocks. When the vertical impact energy reaches a certain level, the rock blocks are in a state of relative vibration separation and, in consequence, reduce the normal force on the contact surface. When the degree of relative vibration separation between the blocks is the largest, the normal force on the contact surface reaches the minimum value. As a result, the effect of "friction disappearance" is generated between the rock blocks. The minimum normal force on the contact surface under different lithology is shown in Table 8.
The minimum normal force on the contact surface and the occurrence time of the minimum normal force are affected by block lithology. It can be seen from Table 8 that the minimum normal force on the contact surface of complex lithology combination is smaller than that of single lithology combination (all blocks are sandstone). The minimum normal force of the coal-rock combination (combination 2) is the smallest: $73.1 \mathrm{~N}$. It is longer than the rock mass, i.e., combination 1 and combination 3, by 0.89 times and by 0.84 times. Combined with Figure 16, the occurrence time of the minimum normal force on the contact surface of complex lithology combination is shorter than that of single lithology combination. In Figure 16, the occurrence time of the minimum normal force of single lithology combination (Figure 16(a)) is $63.4 \mathrm{~ms}$ while that of complex lithology combinations (Figures 16(b)-16(d)) is $38.3 \mathrm{~ms}, 15.6 \mathrm{~ms}$, and $51.5 \mathrm{~ms}$, respectively. Among them, the occurrence time of the minimum normal force of the coal-rock combination (combination 2) is shorter than that of the rock mass (combination 1 and combination 3 ) by 0.41 times and 0.30 times, respectively.

Therefore, it can be claimed that block lithology affects the anomalously low-friction effect. Additionally, coal-rock combination is more prone to the anomalously low-friction effect than the rock mass. Under the actual working conditions, deep coal-rock layer is more prone to interlayer sliding instability than the rock mass layer when they are affected by roof fracture and horizontal disturbance, and the possibility of the deep coal-rock layer inducing anomalously low-friction rock burst is higher.

\section{Conclusions}

Using FLAC3D numerical simulation software, the influence of the vertical impact energy, confining pressure, and lithology on the anomalously low-friction effect of the block rock mass is investigated. The research conclusions are as follows:

(1) With the increase of the vertical impact energy, the horizontal residual displacement increases linearly, the displacement amplitude of the working block increases by the exponential function, and the minimum normal force on the contact surface decreases linearly. The results indicate that the vertical impact energy affects the anomalously low-friction effect. The greater the energy is, the anomalously low-friction effect between the blocks is more likely to occur. 
(2) With the increase of the confining pressure, the horizontal residual displacement and displacement amplitude of the working block decrease by logarithmic and linear functions, and the minimum normal force on the contact surface increases linearly. The smaller the confining pressure is, the anomalously low-friction effect between the blocks is more prone to occur.

(3) Rock block lithology affects the anomalously lowfriction effect, and coal-rock combination is more prone to the anomalously low-friction effect than the rock mass.

\section{Data Availability}

The data used to support the findings of this study are included within the article.

\section{Conflicts of Interest}

The authors declare no conflicts of interest.

\section{Acknowledgments}

This research was financially supported by the National Key R\&D Program of China (2016YFC0600901), the National Natural Science Foundation of China (51974148 and 51874165), and Liaoning Revitalization Talents Program (XLYC1807130).

\section{References}

[1] Q. H. Qian, "The characteristic scientific phenomena of engineering response to deep rock mass and the implication of deepness," Journal of East China Institute of Technology, vol. 27, no. 1, pp. 1-5, 2004.

[2] M. V. Kurlenya, V. V. Adushkin, and V. N. Oparin, "Alternating reaction of rocks to dynamic action," Doklady ANSSSR Geotechnics, vol. 26, no. 2, pp. 323-329, 1992.

[3] M. V. Kurlenya, V. N. Oparin, and V. I. Vostrikov, "Effect of anomalously low friction in block media," Journal of Applied Mechanics and Technical Physics, vol. 40, no. 6, pp. 1116-1120, 1999.

[4] K. Ujiie, "Fault rock analysis of the northern part of the Chelungpu Fault and its relation to earthquake faulting of the 1999 Chi-Chi earthquake, Taiwan," The Island Arc, vol. 14, no. 1, pp. 2-11, 2005.

[5] B. G. Tarasov and M. F. Randolph, "Frictionless shear at great depth and other paradoxes of hard rocks," International Journal of Rock Mechanics and Mining Science, vol. 45, no. 3, pp. 316-328, 2007.

[6] Y. Boneh, A. Sagy, and Z. Reches, "Frictional strength and wear-rate of carbonate faults during high-velocity, steadystate sliding," Earth and Planetary Science Letters, vol. 381, pp. 127-137, 2013.

[7] V. A. Saraikin, A. G. Chernikov, and E. N. Sher, "Wave propagation in two-dimensional block media with viscoelastic layers (theory and experiment)," Journal of Applied Mechanics and Technical Physics, vol. 56, no. 4, pp. 688-697, 2015.

[8] G. Rashed and S. S. Peng, "Change of the mode of failure by interface friction and width-to-height ratio of coal specimens," Journal of Rock Mechanics and Geotechnical Engineering, vol. 7, no. 3, pp. 256-265, 2015.

[9] A. Tajduś, M. Cała, and K. Tajduś, "The influence of normal fault on initial state of stress in rock mass," Studia Geotechnica et Mechanica, vol. 38, no. 1, pp. 109-121, 2016.

[10] Y. Ito, M. J. Ikari, K. Ujiie, and A. Kopf, "Coseismic slip propagation on the Tohoku plate boundary fault facilitated by slip-dependent weakening during slow fault slip," Geophysical Research Letters, vol. 44, no. 17, pp. 8749-8756, 2017.

[11] K. I.-I. Eshiet and Y. Sheng, "The role of rock joint frictional strength in the containment of fracture propagation," Acta Geotechnica, vol. 12, no. 4, pp. 897-920, 2017.

[12] A. J. Das, P. K. Mandal, R. Bhattacharjee, S. Tiwari, A. Kushwaha, and L. B. Roy, "Evaluation of stability of underground workings for exploitation of an inclined coal seam by the ubiquitous joint model," International Journal of Rock Mechanics and Mining Sciences, vol. 93, pp. 101-114, 2017.

[13] H. Lomas, R. Richard, and T. Thorley, "Tribological testing of metallurgical coke: coefficient of friction and relation to coal properties," Energy \& Fuels, vol. 93, 2019.

[14] S. H. Prassetyo, M. A. Irnawan, and G. Simangunsong, "New coal pillar strength formulae considering the effect of interface friction," International Journal of Rock Mechanics and Mining Sciences, vol. 123, 2019.

[15] E. R. Heimisson, E. M. Dunham, and M. Almquist, "Poroelastic effects destabilize mildly rate-strengthening friction to generate stable slow slip pulses," Journal of the Mechanics and Physics of Solids, vol. 130, pp. 262-279, 2019.

[16] M. A. Pirzada, H. Roshan, and H. Sun, "Effect of contact surface area on frictional behaviour of dry and saturated rock joints," Journal of Structural Geology, vol. 130, 2020.

[17] H. Wu, Q. Fang, and Y. D. Zhang, "Mechanism of anomalously low friction phenomenon in deep block rock mass," Mining Science and Technology, vol. 19, no. 4, pp. 409-419, 2009.

[18] M. C. He, Y. Wang, and D. Q. Liu, "Experimental study on ultra-low friction effect of granite block based on two-dimensional digital image correlation technique," Journal of China Coal Society, vol. 43, no. 10, pp. 2732-2740, 2018.

[19] H. M. Jiang and J. Li, "Experimental study of sliding behavior of red sandstone blocks under impact loads," Geotechnical Investigation \& Surveying, vol. 46, no. 09, pp. 6-10, 2018.

[20] L. P. Li, W. J. Li, and Y. S. Pan, "Influence of impact disturbance on anomalously low friction rock bursts," Chinese Journal of Rock Mechanics and Engineering, vol. 38, no. 1, pp. 111-120, 2019.

[21] W. D. Ye, Y. Xu, and Y. Li, "Weak structure of surrounding rock and support technology in inclined roadway crossing coal seam," Safety in Coal Mines, vol. 46, no. 9, pp. 221-224, 2015.

[22] J. P. Zuo, X. Wei, and J. Wang, "Investigation of failure mechanism and model for rocks in deep roadway under stress gradient effect," Journal of China of Mining \& Technology, vol. 47, no. 03, pp. 478-485, 2018.

[23] Z. Gao, Evolution Law of Plastic Zone and Burst Failure Mechanism of Gateway in Yima Coalfield, China University of Mining \& Technology, Beijing, China, 2018. 